\title{
The effect of oxygen on fermentation of sucrose by rumen micro-organisms in vitro
}

\author{
BY J. W. CZERKAWSKI AND GRACE BRECKENRIDGE \\ Hannah Dairy Research Institute, Ayr
}

(Received 9 May 1968-Accepted 26 August 1968)

\begin{abstract}
1. The effect of oxygen on the fermentation of sucrose by mixed rumen micro-organisms in vitro was studied by adding oxygen to the gas phase in three ways: at the beginning of incubation, at two hourly intervals during incubation and continuously.

2. The additions of oxygen had no measurable effect on the utilization of sucrose or on the production of carbon dioxide, steam-volatile acids and particulate organic matter by the micro-organisms. The addition of oxygen at the beginning of incubation inhibited methane production and increased the accumulation of hydrogen. Similar but much less pronounced changes occurred when the oxygen was infused continuously.

3. In all the experiments there was a net uptake of oxygen by micro-organisms. When large amounts of oxygen were present in the gas phase the rates of uptake were proportional to these amounts. When small amounts of oxygen were added, the rates of uptake were independent of the amount added and had a value of approximately $5 \mathrm{ml} / \mathrm{h}$ when $100 \mathrm{ml}$ of strained rumen contents were incubated.
\end{abstract}

It has long been accepted that the microbial system of the rumen is strictly anaerobic, and that only certain species of rumen micro-organisms can survive for any length of time when exposed to more than a few parts per million of oxygen. For instance, coliform organisms which are facultative anaerobes have been isolated from the rumen (Krishnamurti \& McElroy, 1967). The belief that most of the microorganisms in the rumen are anaerobic was supported by the isolation and cultural studies of several microbial species and by the demonstration that these organisms required complete anaerobiosis (see review by Hungate, Bryant \& Mah, 1964). However, as relatively little is known about the true nutritional requirements of the anaerobic organisms, in some instances, it might be the lack of some essential nutrients rather than the direct effect of oxygen that makes these organisms appear so strictly anaerobic.

The strict anaerobiosis of the rumen has been assumed rather than proved, and a consideration of various factors involved suggests that the system may not be completely anaerobic. Small proportions of oxygen $(0.5-1.0 \%)$ are usually found in the rumen gases (McArthur \& Miltimore, 196r; Czerkawski \& Clapperton, 1968). This concentration of oxygen represents a tension that is quite lethal to many microbial species, particularly the ones that are responsible for the production of methane. It has been suggested (Czerkawski, I968) that oxygen may enter the rumen with food, with saliva or by diffusion from the blood. The latter may be of considerable importance as a source of oxygen because the rumen tissues have a rich blood supply, with many of the capillary vessels closer to the lumen than $0.05 \mathrm{~mm}$ (Dobson, Brown, Dobson \& Phillipson, I956).

It is difficult to test the hypothesis that oxygen diffuses from the blood into the 
rumen by experiments in vivo, although some indirect attempts to do this have been made. Broberg (1958) introduced oxygen into the rumen of sheep and observed only temporary changes in the $\mathrm{rH}$. In fact, not until hydrogen peroxide was added, did the changes last longer than $\mathrm{I} h$. The apparent resistance of the rumen fermentation to oxygen in vivo was confirmed recently (J. L. Clapperton, unpublished results). Up to 401 . of oxygen per day bubbled into the rumen of sheep failed to produce any significant changes in methane production or in the apparent digestibility of the dry matter of the diet.

Experiments in vitro have shown that moderate amounts of oxygen do not affect the production of steam-volatile acids or ammonia (Baldwin \& Emery, 1959) and that oxygen is actively taken up by rumen contents (Broberg, 1957). The object of the present experiments was to investigate the quantitative aspects of utilization of oxygen by rumen micro-organisms in vitro and the effects that oxygen might have on the patterns of fermentation.

\section{EXPERIMENTAL}

\section{Source of rumen liquor}

Rumen liquor was obtained from two sheep, each with a rumen fistula. The sheep were given a diet of sugar-beet pulp $(500 \mathrm{~g}$ at $09.00 \mathrm{~h})$ and hay $(500 \mathrm{~g}$ at $\mathrm{I} 6.00 \mathrm{~h})$. Samples of rumen contents were removed from the rumen shortly before the morning feed. The contents were strained directly through muslin (Czerkawski \& Breckenridge, 1969 ), brought to the laboratory and placed in a water bath at $39^{\circ}$. A slow stream of gas $\left(5 \% \mathrm{CO}_{2}\right.$ in $\left.\mathrm{N}_{2}\right)$ was passed through the strianed contents for at least $30 \mathrm{~min}$ before their introduction into the artificial rumen. The inocula were withdrawn with a $100 \mathrm{ml}$ syringe, while the stock rumen contents were stirred by increasing the rate of gassing to ensure that each vessel received the same type of microorganisms.

\section{Apparatus and methods}

The artificial rumen described in the preceding paper (Czerkawski \& Breckenridge, 1969) was used. In this apparatus it was impossible to eliminate oxygen completely from the gas phase in a short time. Exploratory experiments indicated that small amounts of oxygen $(0.3 \%, \mathrm{v} / \mathrm{v}$, or less in the gas phase) had no measurable effect on the pattern of fermentation and in control experiments attempts were made to keep the oxygen concentration below this level.

The gas was analysed as described by Czerkawski \& Clapperton (r968) and the analytical procedures for the determination of steam-volatile acids and sugar were as described by Czerkawski \& Breckenridge (1969). Samples of the incubation mixtures withdrawn from the artificial rumen were fractionated as follows: two drops of saturated $\mathrm{HgCl}_{2}$ were added to each, and the samples were centrifuged at ${ }_{5} 5000 \mathrm{~g}$ for $20 \mathrm{~min}$. The residues were resuspended in volumes of water equal to the original volumes and centrifuged again. The supernatant fluids were pooled and used for the estimation of sugar and steam-volatile acids (Czerkawski \& Breckenridge, 1969). In addition, lactate was determined by the diffusion method of Conway (1962). The 
residues were dried at $105^{\circ}$, weighed, incinerated and weighed again to give an estimate of the particulate organic matter.

\section{Experimental design}

The oxygen was added to the reaction vessels in three different ways, and the methods and nominal amounts added are summarized in Table $\mathrm{I}$. The starting volume of the gas $\left(5 \% \mathrm{CO}_{2}\right.$ in $\left.\mathrm{N}_{2}\right)$ at the beginning of the experiments was $640 \mathrm{ml}$ and, since the largest amount of $\mathrm{O}_{2}$ added was $60 \mathrm{ml}$, the initial concentration of $\mathrm{O}_{2}$ was about $9 \%$, i.e. almost half the oxygen content of air. The greatest amount of oxygen added was in Expt 3 but, since the amount ranged from o at the start to $120 \mathrm{ml}$ at the end of incubation, the mean amounts of oxygen are similar to those in Expt $x$.

Table I. Methods of addition and amounts of oxygen added to the gas phase (starting volume $640 \mathrm{ml}$ ) during incubation of rumen liquor in vitro

\begin{tabular}{|c|c|c|c|}
\hline \multirow[b]{2}{*}{ Expt no. } & \multirow[b]{2}{*}{ Method of addition } & \multicolumn{2}{|c|}{$\begin{array}{l}\text { Nominal amounts of } \\
\text { oxygen added }(\mathrm{ml})\end{array}$} \\
\hline & & At the start & $\begin{array}{l}\text { Total added } \\
\text { during } 6 \mathrm{~h}\end{array}$ \\
\hline I & $\begin{array}{l}\text { Oxygen added at the } \\
\text { start of the experiment }\end{array}$ & $30-60$ & $30-60$ \\
\hline 2 & $\begin{array}{l}\text { Oxygen added in three } \\
\text { steps after } 0,2 \text { and } 4 \mathrm{~h}\end{array}$ & $15^{-2} 5$ & $45-75$ \\
\hline 3 & $\begin{array}{l}\text { Oxygen added con- } \\
\text { tinuously at constant rate }\end{array}$ & 0 & $60-120$ \\
\hline
\end{tabular}

Expt I. The oxygen was infused into the circulating gas during 4-5 min at the beginning of the experiment. The experiment was repeated some days later and, except for some small differences, similar results were obtained. The small differences were probably due partly to the usual microbial variations that occur in the rumen and partly because it was difficult to strain the contents to exactly the same extent on both occasions. Because of these differences it was not practicable to average the results of replicate experiments, and the results of only one of them are reported.

Expt 2. Although the total amounts of oxygen added to various reaction vessels were similar to those that were added in Expt $I$, they were added in three steps at three different times. At each time the oxygen was infused over a period of $\mathrm{I} \cdot 5 \mathrm{~min}$.

Expt 3 . The oxygen was infused almost continuously at 10,15 and $2 \mathrm{I} \mathrm{ml} / \mathrm{h}$, except for short intervals when the infusion apparatus was reset and the syringes were refilled with oxygen. It seemed advisable to use relatively small syringes and refill them frequently to minimize faulty inputs that might be caused by temporary changes in pressure during sampling. Sampling of the incubation mixtures was confined to the short intervals between infusions.

\section{RESULTS \\ Expt $\mathrm{I}$}

The total gas production was not significantly affected by the addition of oxygen. The apparent initial rates of gas production were $86,73,62$ and $58 \mathrm{ml} / \mathrm{h}$ when $0,25,50$ 
and $69 \mathrm{ml}$ of oxygen were added respectively, but when these were corrected for the uptake of added oxygen (see below), the rates were $86,83,77$ and $76 \mathrm{ml} / \mathrm{h}$ in the control and the three experimental vessels. Irrespective of the amount of oxygen added, gas production tended to be $230-250 \mathrm{ml}$ after $6 \mathrm{~h}$ of incubation.

The amounts of oxygen in the gas phase at any given time are shown in Fig. $I$. Clearly, the amount of oxygen utilized was approximately proportional to the

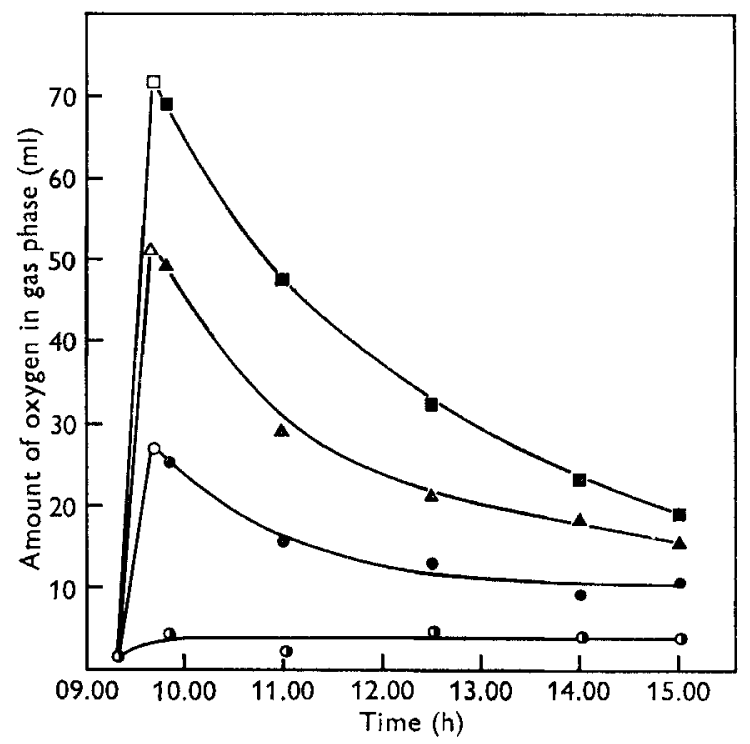

Fig. 1. Amounts of oxygen in the gas phase during fermentation of sucrose. Each vessel contained $200 \mathrm{ml}$ of artificial saliva, $200 \mathrm{ml}$ of water, $100 \mathrm{ml}$ of strained rumen contents, $1.5 \mathrm{~g}$ sucrose and $0.2 \mathrm{~g}$ ammonium carbonate. The oxygen was infused during $4.5 \mathrm{~min}$, starting at $09.35 \mathrm{~h}$. -1 , control; $-1,25 \mathrm{ml} \mathrm{O}$ added; $\Delta-\Delta, 50 \mathrm{ml} \mathrm{O}$ added; $\square, 69 \mathrm{ml} \mathrm{O}_{2}$ added. The open symbols represent the true initial amounts of oxygen, i.e. the amounts added plus $2 \mathrm{ml}$ already in the gas phase.

amounts added initially (about $66 \mathrm{ml}$ ultilized/100 $\mathrm{ml}$ oxygen added). The total amount of oxygen rather than its concentration in the gas phase was important under the conditions used, since other experiments, not included here, gave similar results when the concentration of oxygen was varied by altering the total initial volume of gas while the amount of oxygen was kept constant.

The methane production was inhibited approximately in proportion to the amount of oxygen added (Fig. 2). It should be noted, however, that even with the largest amount of added oxygen, the rate of methane production was not negligible. The amounts of hydrogen in the gaseous phase are shown by the lower curves (Fig. $2 b$ ). Only small amounts of hydrogen were formed in the control vessel, and the amounts formed increased with the amount of oxygen added. It is clear that there was a correlation between the accumulation of hydrogen and the inhibition of methane production. However, in this and in other experiments there was little evidence of the stoichiometry that would be expected from the equation, $\mathrm{CO}_{2}+4 \mathrm{H}_{2} \rightarrow \mathrm{CH}_{4}+$ ${ }_{2} \mathrm{H}_{2} \mathrm{O}$ (Carroll \& Hungate, 1955). 
The amounts of lactate produced were much smaller than the amounts of steamvolatile acids (Fig. 3). Lactate decreased during the latter part of the incubation and the rates of its removal seemed to be inversely related to the amounts of oxygen added.

The concentrations of steam-volatile acids increased rapidly at first and then more slowly and there were no significant differences due to the addition of oxygen (Fig. 3). Similarly, the rates of production of carbon dioxide and the rate of removal of sucrose expressed as hexose did not seem to be affected by the addition of oxygen to the gaseous phase (Fig. 4).

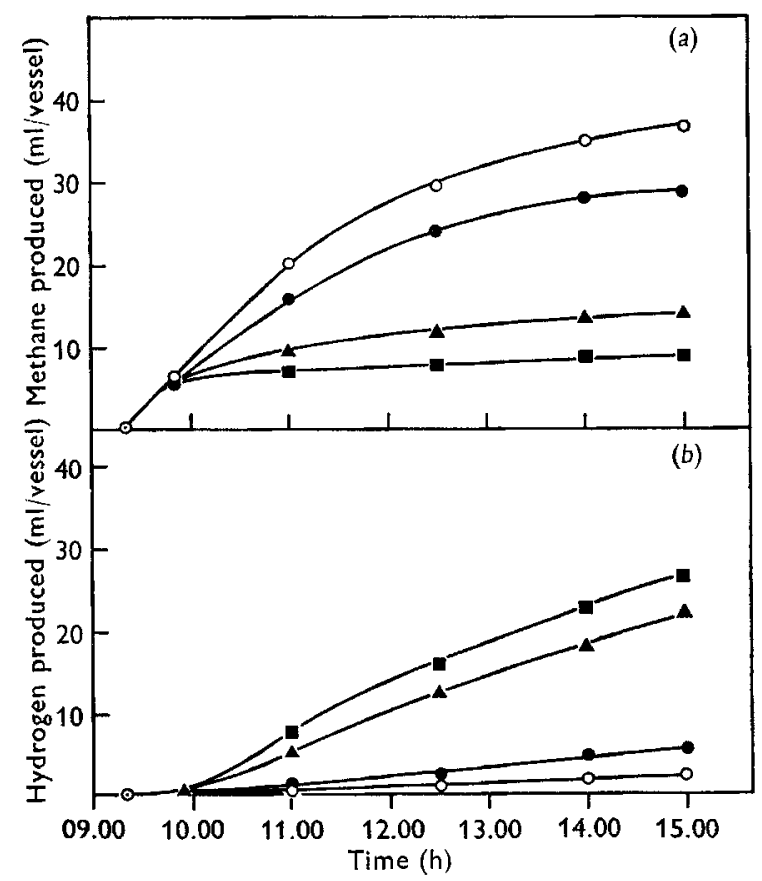

Fig. 2. Effect of oxygen on production of $(a)$ methane and $(b)$ hydrogen during fermentation of sucrose. $\mathrm{O}-\mathrm{O}$, control; $-0,25 \mathrm{ml} \mathrm{O}_{2}$ added; $\Delta-\Delta, 50 \mathrm{ml} \mathrm{O}$ added; $-\square, 69 \mathrm{ml} \mathrm{O}_{2}$ added.

The concentrations of particulate organic matter and the molar proportions of steam-volatile acids are shown in Tables 2 and 3. There was a progressive increase in the particulate organic matter in all the experiments, and the addition of various amounts of oxygen to the gas phase had no significant effect on the increase (Table 2). Similarly, the addition of oxygen did not significantly affect the changes in the concentrations of steam-volatile acids (Fig. 3) or the molar proportions of acetic, propionic and butyric acids (Table 3 ). The ratio of acetic to propionic acid tended to decrease with time in all the experiments, but the molar proportion of butyric acid did not change markedly during incubation except at the end of incubation, when it increased. The steam-volatile acids also contained $\mathrm{I}-2 \%$ isovaleric acid, $0.5-\mathrm{I} \cdot 0 \%$ valeric acid and even smaller amounts of isobutyric acid. There were no significant changes in these minor components either with time of incubation or due to treatments. 


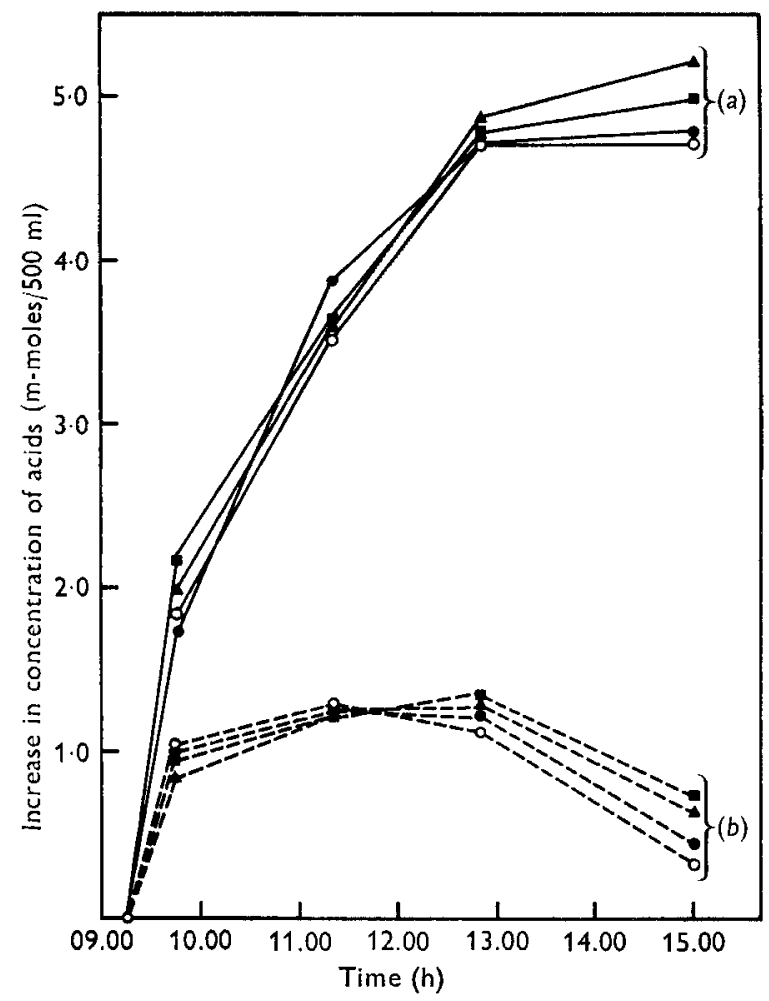

Fig. 3. Increase in the concentration of steam-volatile acids (full curves) and the concentration of lactic acid (broken curves) during fermentation of sucrose. The mean initial concentration of steam-volatile acids in all vessels was $6.30 \pm 0.08 \mathrm{~m}$-moles $/ 500 \mathrm{ml}$. $0-0$, control; $-\bullet, 25 \mathrm{ml} \mathrm{O}_{2}$ added; $\boldsymbol{\Delta}-\boldsymbol{\Delta}, 50 \mathrm{ml} \mathrm{O}_{2}$ added; $\square-\mathbf{\square}, 69 \mathrm{ml} \mathrm{O}_{2}$ added.

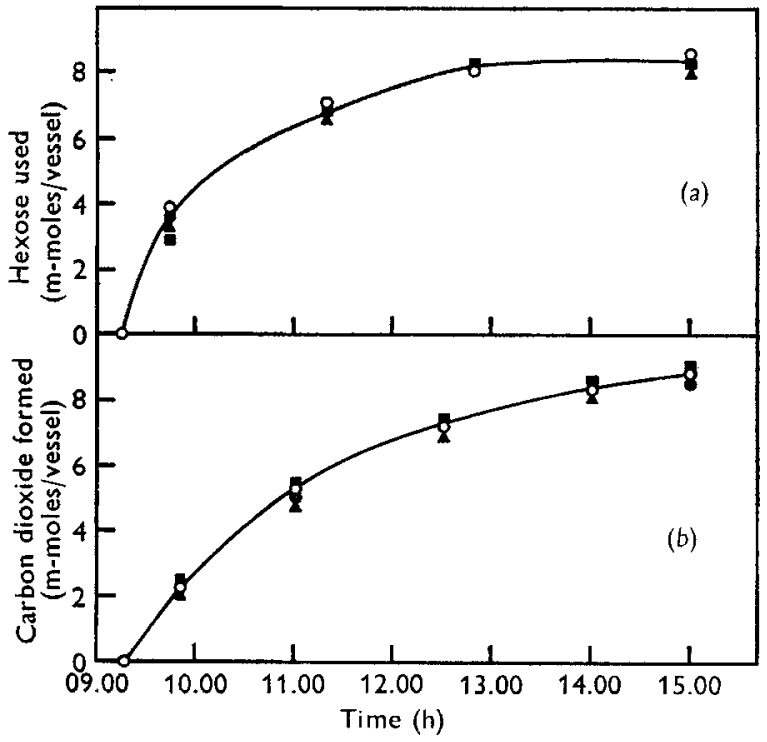

Fig. 4. Amounts of (a) sugar utilized and (b) carbon dioxide produced during fermentation of sucrose. The experimental details are the same as given in Figs. $1-3$. $\mathrm{O}-\mathrm{O}$, control; $25 \mathrm{ml} \mathrm{O}_{2}$ added; $\Delta-\Delta, 50 \mathrm{ml} \mathrm{O}_{2}$ added; $\mathbf{-}, 69 \mathrm{ml} \mathrm{O}_{2}$ added. 
Table 2. Concentration ( $\mathrm{mg} / 500 \mathrm{ml}$ reaction mixture) of particulate organic matter during fermentation of sucrose by rumen micro-organisms when o (control)-69 $\mathrm{ml} \mathrm{O}_{2}$ were added to the reaction mixture

Time (min)

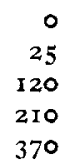

$$
\begin{gathered}
\text { Control } \\
576 \\
\text { IO1 } 2 \\
\text { 1030 } \\
1173 \\
\text { I085 }
\end{gathered}
$$

\begin{tabular}{|c|c|c|c|c|c|c|c|c|c|c|c|c|}
\hline \multirow{2}{*}{$\begin{array}{l}\text { Time } \\
\text { (min) }\end{array}$} & \multicolumn{3}{|c|}{ Control } & \multicolumn{3}{|c|}{$25 \mathrm{ml} \mathrm{O}_{2}$} & \multicolumn{3}{|c|}{$50 \mathrm{ml} \mathrm{O}_{2}$} & \multicolumn{3}{|c|}{$69 \mathrm{ml} \mathrm{O}$} \\
\hline & $\mathrm{C}_{2}$ & $\mathrm{C}_{3}$ & $\mathrm{C}_{4}$ & $\mathrm{C}_{2}$ & $\mathrm{C}_{3}$ & $\mathrm{C}_{4}$ & $\mathrm{C}_{2}$ & $\mathrm{C}_{3}$ & $\mathrm{C}_{\mathrm{i}}$ & $\mathrm{C}_{2}$ & $\mathrm{C}_{3}$ & $\mathrm{C}_{4}$ \\
\hline 0 & $69 \cdot I$ & I 8.2 & $8 \cdot 9$ & - & - & - & 一 & - & - & $67 \cdot 8$ & $18 \cdot 3$ & $\mathrm{rI} \cdot 6$ \\
\hline 25 & 68.0 & $18 \cdot \mathrm{I}$ & I I 2 & $64 \cdot 2$ & $20 \cdot 1$ & $12 \cdot 6$ & $64 \cdot 9$ & $20 \cdot 3$ & 10.9 & 66.5 & $19 \cdot 3$ & II'5 \\
\hline 120 & $64 \cdot 3$ & 23.6 & $10 \cdot 3$ & 64.0 & $22 \cdot 3$ & II 4 & 66.9 & 20.8 & 10.4 & 66.0 & 20.8 & II $\cdot I$ \\
\hline 210 & $65 \cdot 7$ & $22 \cdot 2$ & $10 \cdot 4$ & $64 \cdot I$ & $22 \cdot 3$ & I I 4 & $59 \cdot 3$ & $24 \cdot 5$ & 13.9 & $65 \cdot I$ & $21 \cdot 5$ & I I 5 \\
\hline 370 & $56 \cdot I$ & $28 \cdot 5$ & 13.1 & $55 \cdot 4$ & $29 \cdot I$ & 13.7 & $53 \cdot 4$ & $28 \cdot I$ & 15.9 & $58 \cdot 4$ & $25 \cdot 6$ & 13.7 \\
\hline
\end{tabular}

$50 \mathrm{ml} \mathrm{O}_{2}$
625
932
1109
1096
r 115

$69 \mathrm{ml} \mathrm{O}_{2}$

632
897
1096
I 190
1095
- when o (control)-69 $\mathrm{ml} \mathrm{O}_{2}$ were added to the reaction mixture. The minor components (isovaleric, valeric and isobutyric acids) are not included

* $\mathrm{C}_{2}$, acetic acid; $\mathrm{C}_{8}$, propionic acid; $\mathrm{C}_{4}$, butyric acid.

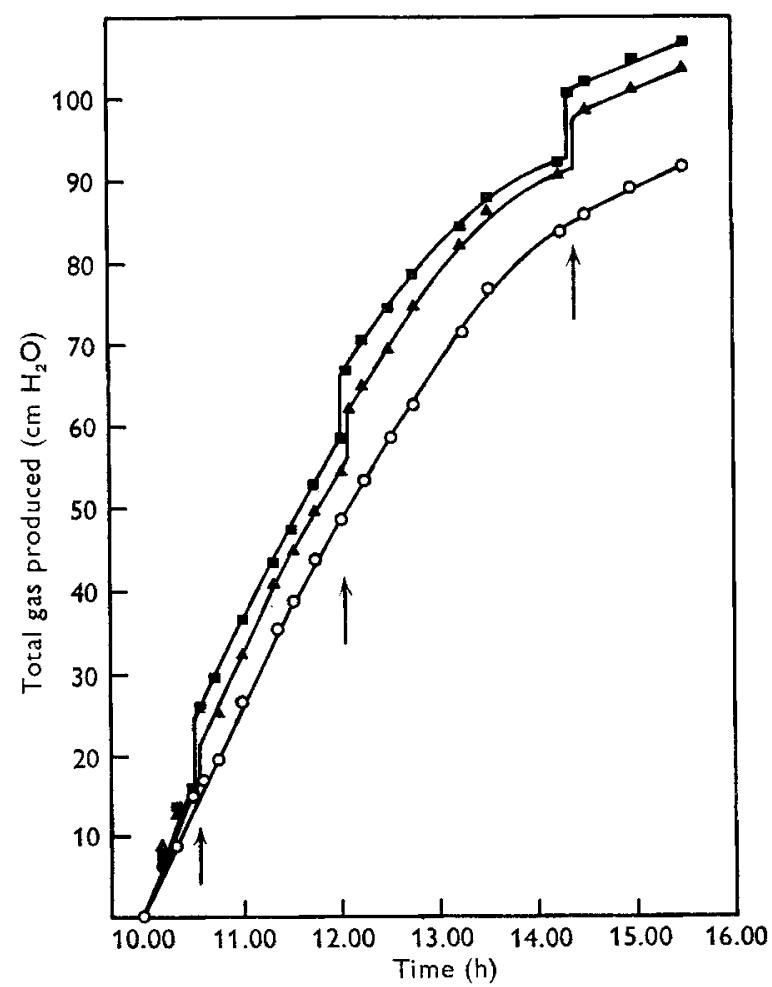

Fig. 5. Total gas production during fermentation of sucrose by rumen micro-organisms when the oxygen was added stepwise. $\mathrm{O}-\mathrm{O}$, control-no $\mathrm{O}_{2}$ added; $\Delta-\Delta$, I $5 \mathrm{ml} \mathrm{O}_{2}$ added during $\mathrm{I} .5 \mathrm{~min}$ at the times indicated by arrows; $\square, 26 \mathrm{ml} \mathrm{O}_{2}$ added at the times indicated. 


\section{Expt 2}

The results of gas analyses are given in Figs. 5 and 6 . The amounts of total gas produced are shown in Fig. 5, where the steps shown in two of the curves correspond to the short infusions of oxygen.

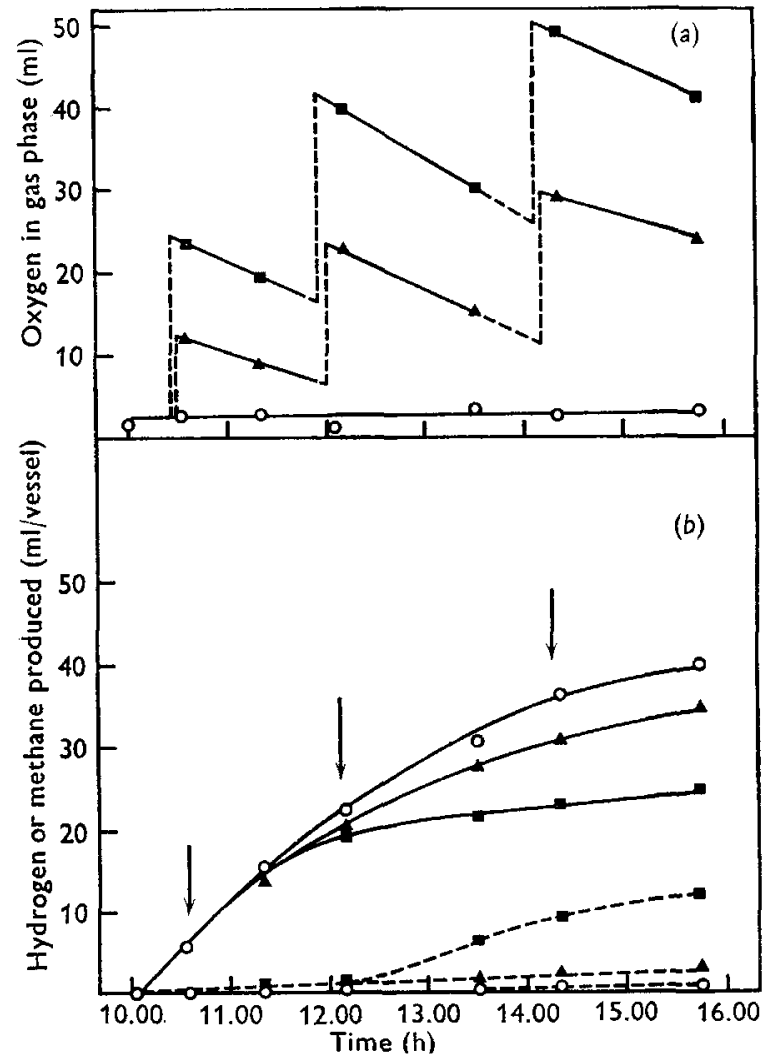

Fig. 6. (a) Amounts of oxygen in the gas phase when it was added stepwise, showing its uptake during fermentation of sucrose by rumen micro-organisms. (b) Effect of various amounts of oxygen added stepwise (arrows) on the production of methane (full curves) and hydrogen (broken curves). $\mathrm{O}-\mathrm{O}$, control--no $\mathrm{O}_{2}$ added; $\mathbf{\Lambda}-\mathbf{\Lambda}, 15 \mathrm{ml} \mathrm{O}_{2}$ per step; a-, $26 \mathrm{ml} \mathrm{O}_{2}$ per step.

There was a definite uptake of oxygen after every addition (Fig. $6 a$ ), but the uptake was not complete and oxygen tended to accumulate even with the lower level of infusion. The first infusions had little or no effect on methane production (Fig. 6b). However, further additions of oxygen resulted in progressive inhibition of methane production and in accumulation of hydrogen. Neither the rate of disappearance of sugar nor of the production of $\mathrm{CO}_{2}$ was affected significantly by the addition of oxygen at three different times of incubation. It was found also that there were no significant treatment changes in the amounts of particulate organic matter, concentrations of steam-volatile acids or $\mathrm{pH}$, so these results are not given here.

The concentrations of lactate rose from about $0.02 \mathrm{~m}-\mathrm{mole} / 500 \mathrm{ml}$ at the start of 
incubation to a maximum of $0.7-0.8 \mathrm{~m}$-mole $/ 500 \mathrm{ml}$ after $2.5 \mathrm{~h}$ of incubation and dropped to $0.2-0.4 \mathrm{~m}-\mathrm{mole} / 500 \mathrm{ml}$ at the end of incubation. The maximum values were somewhat higher in vessels to which oxygen was added than in the control vessel.

\section{Expt 3}

Values for the total gas production in each vessel are not given in detail. The rates of production of gas during the first half hour of incubation were almost the same in all the vessels. Then they began to diverge and after $2 \mathrm{~h}$ the mean rates were 60,63 ,

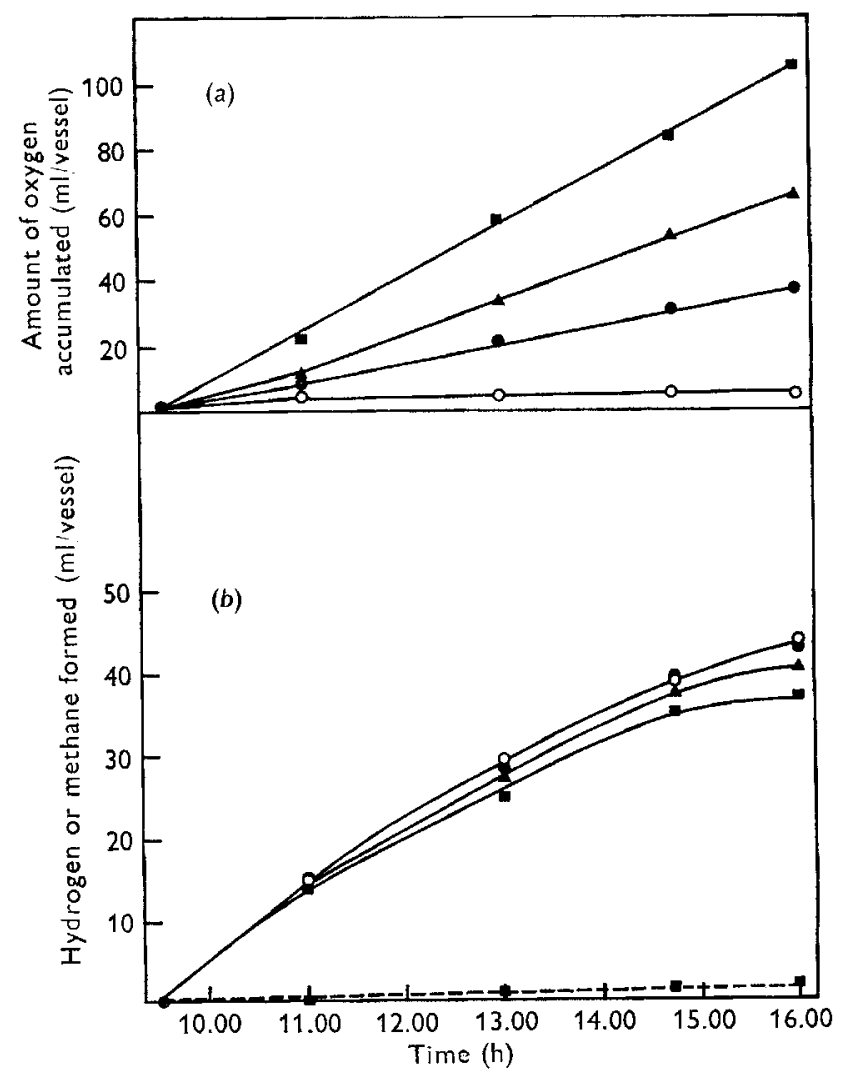

Fig. 7. Fermentation by rumen micro-organisms. (a) Amounts of oxygen in the gas phase when oxygen was infused continuously. (b) Production of methane (full lines) and hydrogen (broken line). $\mathrm{O}-\mathrm{O}$, control-no $\mathrm{O}_{2}$ added; - $-\mathrm{O}_{2}$ added at $\mathrm{IO} \mathrm{ml} / \mathrm{h} ; \boldsymbol{\Delta}-\mathbf{\Lambda}, \mathrm{O}_{2}$ added at I5 $\mathrm{ml} / \mathrm{h} ; \mathbf{m}-\mathrm{C}, \mathrm{O}_{2}$ added at $2 \mathrm{I} \mathrm{ml} / \mathrm{h}$.

66 and $7 \mathrm{Iml} / \mathrm{h}$ when $0,10,15$ and $21 \mathrm{ml} / \mathrm{h}$ of oxygen were infused respectively. When corrections were made for accumulation of oxygen, the mean initial rate of gas

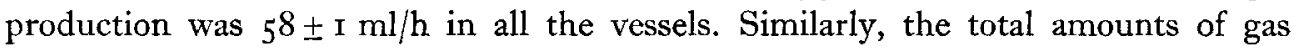
apparently produced after $6 \mathrm{~h}$ of incubation were 259, 286, 319 and $350 \mathrm{ml}$ when $0,10, I_{5}$ and $2 \mathrm{I} \mathrm{ml}$ of oxygen were infused per hour, respectively, and after corrections were made for accumulated oxygen the mean amount for all four experiments was $256 \pm 2 \mathrm{ml}$. The actual extent of accumulation of oxygen is shown in Fig. $7 a$. 
Table 4. Inhibition of methane production when oxygen was infused continuously into the gas phase of the reaction vessels

(The results are the means and standard errors for three separate experiments. Samples of rumen liquor for these experiments were obtained on different days)

$\begin{array}{cc}\begin{array}{c}\text { Rate of } \\ \text { infusion } \\ (\mathrm{ml} \mathrm{O} / \mathrm{h})\end{array} & \begin{array}{c}\text { Inhibition of } \\ \mathrm{CH}_{4} \text { production } \\ (\%)\end{array} \\ \text { I0 } & \mathrm{I} \cdot 3 \pm 3.06 \\ \text { I5 } & 7 \cdot 3 \pm 3 \cdot 2 \\ 2 \mathrm{r} & \mathrm{I} \cdot 7 \pm 2 \cdot 2\end{array}$

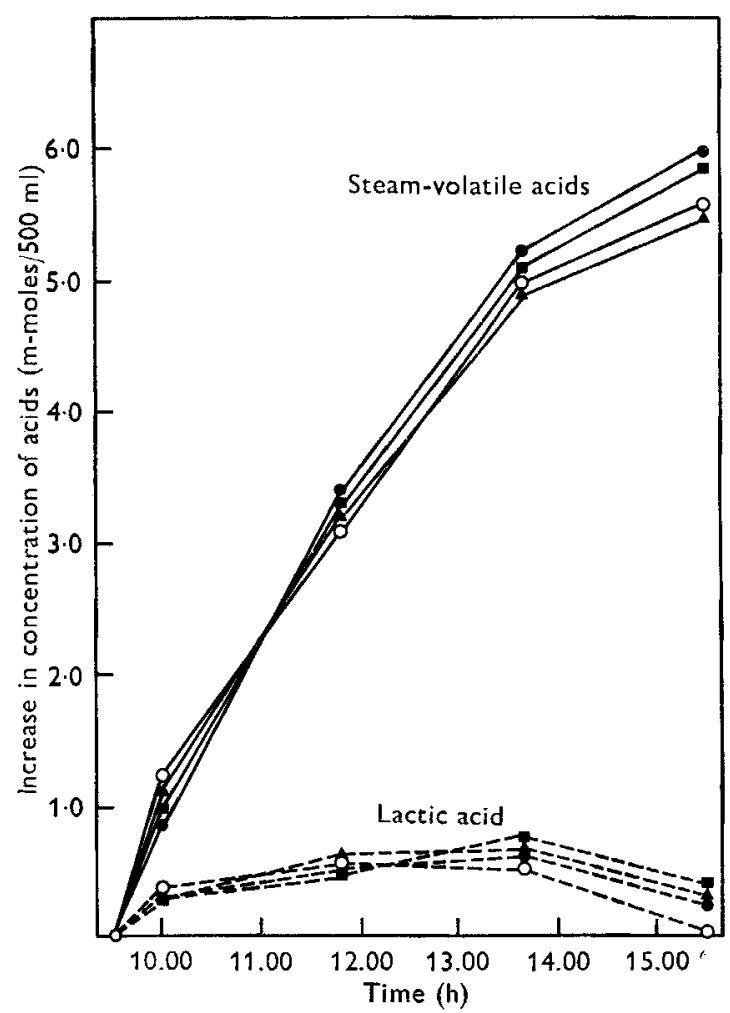

Fig. 8. Production of steam-volatile acids and lactic acid during fermentation of sucrose by rumen micro-organisms when oxygen was infused continuously. $\mathrm{O}-\mathrm{O}$, control- no $\mathrm{O}_{2}$ added; - $\mathrm{O}_{2}$ added at $\mathrm{I} O \mathrm{ml} / \mathrm{h} ; \boldsymbol{\Lambda}-\boldsymbol{\Lambda}, \mathrm{O}_{2}$ added at $\mathrm{I} \mathrm{ml} / \mathrm{h} ; \mathbf{\square}-\mathbf{-}, \mathrm{O}_{2}$ added at $2 \mathrm{I} \mathrm{ml} / \mathrm{h}$.

The total amounts of oxygen infused into the gas phase of vessels 1,2 and 3 were 69,103 and $144 \mathrm{ml}$ respectively and the amounts utilized (differences between oxygen added and oxygen accumulated) were approximately 32,38 and $39 \mathrm{ml}$. Thus, the amounts of oxygen utilized under these conditions were almost independent of the level of infusion. The mean rate of utilization of oxygen by $100 \mathrm{ml}$ of rumen liquor was about $5.6 \mathrm{ml} / \mathrm{h}$.

The amounts of methane and hydrogen formed are shown in Fig. $7 b$. In general, both the inhibition of methane production and the accumulation of hydrogen were 
small, even when the largest amounts of oxygen were infused. These results were of sufficient importance to make it desirable to repeat the experiment a number of times. Essentially, the same results were always obtained (Table 4).

The changes in the concentrations of the steam-volatile acids and the concentrations of lactic acid in the reaction mixtures are shown in Fig. 8. Again, the amounts of lactic acid formed were much smaller than the amounts of steam-volatile acids and, again, the concentration pattern for lactic acid implied that it was an intermediate rather than an end-product of fermentation.

Table 5. Concentrations of particulate organic matter and concentrations and molar proportions of steam-volatile acids during fermentation of sucrose by rumen microorganisms: continuous infusion of oxygen

(The results are means and their standard errors for four concurrent incubations in which oxygen was added continuously to the gas phase at various rates. The minor components (isovaleric, valeric and isobutyric acid) were not included. Since there were no differences in the results due to the addition of various amounts of oxygen, the results for the four incubations were pooled)

\begin{tabular}{|c|c|c|c|c|c|}
\hline \multirow{3}{*}{$\begin{array}{l}\text { Time } \\
(\min )\end{array}$} & \multirow{3}{*}{$\begin{array}{c}\text { Particulate } \\
\text { organic } \\
\text { matter } \\
\text { (mg/vessel) }\end{array}$} & \multicolumn{4}{|c|}{ Steam-volatile acids } \\
\hline & & \multirow{2}{*}{$\begin{array}{l}\text { Concentration } \\
\text { (m-equiv./vessel) }\end{array}$} & \multicolumn{3}{|c|}{$\begin{array}{l}\text { Molar proportions } \\
\text { (moles/100 moles) }\end{array}$} \\
\hline & & & Acetic & Propionic & Butyric \\
\hline 0 & $660 \pm 23$ & $6.72 \pm 0.12$ & $69.6 \pm 0.7$ & $19.5 \pm 0.6$ & $9 \cdot I \pm I \cdot O$ \\
\hline I 5 & $1045 \pm 5 x$ & $7 \cdot 71 \pm 0.63$ & $70 \cdot 0 \pm 1 \cdot 0$ & $19 \cdot 0 \pm 1 \cdot 3$ & $8.7 \pm 0.9$ \\
\hline 125 & $1248 \pm 29$ & $10.05 \pm 0.22$ & $66 \cdot 0 \pm 0.9$ & $22 \cdot 8 \pm 0.4$ & $9.3 \pm 0.3$ \\
\hline 235 & $1290 \pm 43$ & I I. $90 \pm 0.48$ & $6_{3} \cdot 4 \pm x \cdot 0$ & $24.9 \pm 0.5$ & $9.9 \pm 0.4$ \\
\hline 345 & $1283 \pm 27$ & $12.56 \pm 0.4 \mathrm{I}$ & $65 \cdot 3 \pm 0 \cdot 8$ & $24.2 \pm 0.5$ & $9 \cdot 0 \pm 0.3$ \\
\hline
\end{tabular}

Table 6. Production of carbon dioxide and utilization of sucrose during fermentation of sucrose by rumen micro-organisms, when various amounts of oxygen were added continuously. Means for the four vessels and their standard errors are given

(The results of analyses of samples from the control vessel in which no oxygen was added and from the vessels in which various amounts of oxygen were infused continuously were pooled and expressed as means and standard errors. It was possible to do this because there were no significant differences due to treatments)

$\begin{array}{ccc}\begin{array}{c}\text { Time of } \\ \text { incubation } \\ \text { (min) }\end{array} & \begin{array}{c}\text { Sucrose utilized } \\ \text { (m-moles hexose/ } \\ \text { vessel) }\end{array} & \begin{array}{c}\text { Carbon dioxide } \\ \text { produced } \\ \text { (m-moles/vessel) }\end{array} \\ 90 & 4.5 \pm 0.2 & 3.9 \pm 0.1 \\ 210 & 7 \cdot 1 \pm 0.3 & 7.7 \pm 0.4 \\ 310 & 8.3 \pm 0.3 & 10.4 \pm 0.3\end{array}$

'The results of determinations of particulate organic matter, of the concentrations of total steam-volatile acids and of the molar proportions of acetic, propionic and butyric acids are summarized in Table 5 . Since there were no differences in the results due to the addition of various amounts of oxygen, the results from the four incubations were pooled. In all four incubations, both the organic matter and total steam-volatile acids increased progressively with time. The ratios of acetic to propionic acid tended 
to decrease with time, and these decreases were not significantly affected by infusion of oxygen.

The production of carbon dioxide and the utilization of sucrose during incubation were not significantly different from control values when various amounts of oxygen were infused continuously. The results of some of the determinations are shown in Table 6 , where the values are the pooled results of four concurrent incubations.

\section{DISCUSSION}

The extreme conditions of Expt $\mathrm{r}$ probably did not resemble the conditions that normally obtain in the rumen. It is unlikely that the bulk of the rumen contents of an animal is ever suddenly confronted with large amounts of oxygen. However, this might occur, in some degree, during rumination. The sheep may spend 6-1o h/day in chewing the cud (Broberg, 1957), and at least part of the contents is exposed to

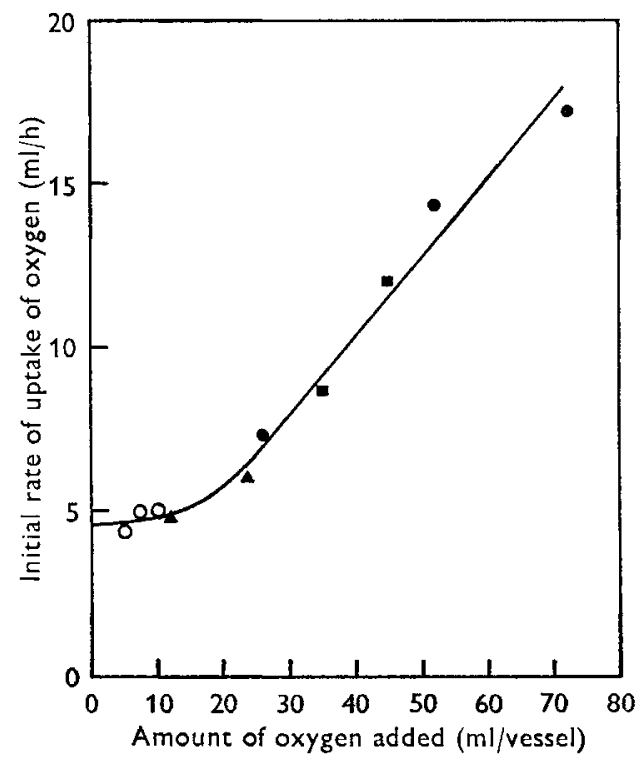

Fig. 9. Effect of the amounts of oxygen added to the gas phase at the start of incubation on the initial uptake of oxygen (mean uptake during the rst hour of incubation). - - , from Expt I $\left(\mathrm{O}_{2}\right.$ added at the start $) ; \boldsymbol{\Delta}-\boldsymbol{\Delta}$, from Expt $2\left(\mathrm{O}_{2}\right.$ added stepwise $)$; $\boldsymbol{\square}-\boldsymbol{E}$, from an experiment not described in this paper (oxygen added at the start); $\mathrm{O}-\mathrm{O}$, from Expt 3 (the mean amounts of $\mathrm{O}_{2}$ after $\mathrm{I} \mathrm{h}$ infusion were taken, i.e. total infused in $\mathrm{I} h$ divided by 2 , and rates of uptake of oxygen were the mean rates for the whole incubation).

oxygen under conditions resembling those in Expt I. The utilization of sucrose and the formation of several end-products of fermentation were not significantly affected by oxygen, but it was fairly obvious that the metabolic pathways concerned with methanogenesis and possibly related pathways were affected. There was considerable inhibition of methane formation and an accumulation of hydrogen and, although there was a correlation between the two phenomena, no obvious stoichiometry was observed. The changes in the concentration of lactate were not markedly different from those of 
the controls. Lactate behaved as an intermediate; its concentration increased during incubation and then decreased. The amounts of lactic acid produced were relatively large in this experiment but, nevertheless, the maximum concentrations were much smaller than the concentrations of steam-volatile acids. The rates of production of the volatile acids, as well as the rates of production of carbon dioxide, were not affected by the addition of oxygen. The total amounts of oxygen added to the system during the period of incubation in Expt 2 were not very different from those added at the start in Expt I, yet the inhibition of methane production and the accumulation of hydrogen were less extensive. Again, there were no significant changes in the other measurements made.

If it be assumed that oxygen diffuses into the rumen from the blood, then the conditions of Expt 3 resembled most closely the condition that might occur in vivo. Although the rate of infusion of oxygen was relatively slow, it accumulated towards the end until its concentration in the gaseous phase was nearly $9 \%$. Yet, the inhibition of methane production was relatively small and only small amounts of hydrogen tended to accumulate.

The amounts of oxygen taken up per unit time in Expts $x$ and 2 were large initially and then they tended to fall off exponentially. The initial rates of uptake as well as the total amounts taken up at any time were approximately proportional to the amounts of oxygen added. However, this proportionality did not seem to apply when small amounts of oxygen were added at the start or infused continuously because then the uptake was considerable and, within limits, independent of the rate of addition. Experiments in which small amounts of oxygen were added at the start $(3-7 \mathrm{ml}$ per vessel) have shown that there was a definite uptake of oxygen, but it was difficult to estimate the actual rate, beyond the fact that in most instances more than $50 \%$ of the added oxygen disappeared during the first hour of incubation.

The initial rates of uptake of oxygen (mean uptake during first hour), where reasonably accurate measurements were possible, are summarized in Fig. 9 in which the values from Expt 3, expressed as the mean rates of uptake during the whole incubation, were plotted for convenience against the mean amount of oxygen infused over the first hour.

It would appear that the initial uptake of oxygen might not vary greatly when small amounts of oxygen are added continuously, but that it increases rapidly when larger amounts are added. The lower limiting rate of uptake, given an excess of oxygen, was approximately $5 \mathrm{ml}$ oxygen/h when $\mathrm{I} \cdot 5 \mathrm{~g}$ sucrose were incubated with roo $\mathrm{ml}$ rumen contents.

If it is assumed that the volume of the rumen contents of a sheep is 71 , and that $1 \cdot 5 \times 70=105 \mathrm{~g}$ of sugar are added to the contents (equivalent to the sheep consuming about $400 \mathrm{~g}$ of sugar-beet pulp), then on the basis of the above results the microorganisms in the rumen of such a sheep might utilize $5 \times 0.07 \times 24=8.41$. oxygen/day when the oxygen is added slowly.

In Expt I, when oxygen was added at the start of incubation in relatively large amounts, and when methane production was inhibited, the oxygen uptake could be accounted for by assuming that the carbohydrate was converted into a product of 
similar or higher oxidation state and that the hydrogen that was not used in reducing $\mathrm{CO}_{2}$ to $\mathrm{CH}_{4}$ reacted with oxygen to give water. Appropriate corrections were made for the small amounts of hydrogen that accumulated. In Expt 2, the inhibition of methane production could not account for all the oxygen utilized, even if it was assumed that the methane formed initially was fully oxidized to carbon dioxide. The inhibition of methane production and the accumulation of hydrogen in Expt 3 were very small and could account for only a small portion of the oxygen taken up. Since none of the other measurements made was significantly affected it must be assumed that the change had taken place elsewhere, e.g. a change in the oxidation-reduction state of the microbial matter, brought about for instance, by a decrease in the content of microbial lipid.

It is well known that under aerobic conditions the dissimulation of sugars results in greater yields of energy than under anaerobic conditions (Hadjipetrou \& Stouthamer, I965). Therefore, the postulated uptake of oxygen in the rumen might be relevant to the metabolism of long-chain fatty acids and to the ruminal interconversion of nutrients.

\section{REFERENCES}

Baldwin, R. L. \& Emery, R. S. (1959). F. Dairy Sci. 42, 914.

Broberg, G. (r957). Nord. VetMed. 9, 942.

Broberg, G. (1958). Nord. VetMed. 10, 263.

Carroll, E. J. \& Hungate, R. E. (1955). Archs Biochem. Biophys. 56, 525.

Conway, E. J. (1962). Microdiffusion Analysis and Volumetric Error, p. 276. London: Crosby, Lockwood and Son Ltd.

Czerkawski, J. W. (1968). Wld Rev. Nutr. Diet. (In the Press.)

Czerkawski, J. W. \& Breckenridge, G. (1969). Br. F. Nutr. 23, 5 I.

Czerkawski, J. W. \& Clapperton, J. L. (1968). Lab. Pract. 17, 994.

Dobson, M. J., Brown, W. C. B., Dobson, A. \& Phillipson, A. T. (1956). Q. Fl exp. Physiol. 41, 247.

Hadjipetrou, L. P. \& Stouthamer, A. H. (1965). \%. gen. Microbiol. 38, 29.

Hungate, R. E., Bryant, M. P. \& Mah, R. A. (1964). A. Rev. Microbiol. r8, 13 I.

Krishnamurti, C. R. \& McElroy, L. W. (1967). Can. F. Anim. Sci. 47, 193.

McArthur, J. M. \& Miltimore, J. E. (rg6r). Can. F. Anim. Sci. 41, I87. 